\title{
Contextos Alfareros de Interacción Social: Lo Local y Lo Foráneo en el Cementerio Inca de Quinta Normal
}

Pottery contexts of social interaction: local and foreign elements in the Inca cemetery of Quinta Normal.

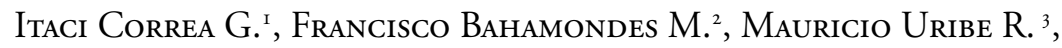
Claudia Solervicens C. ${ }^{4}$

\section{RESUMEN}

Se dan a conocer 17 vasijas cerámicas, que constituyen parte de las ofrendas de siete entierros del Periodo Incaico registrados en el sitio Estación Intermodal Quinta Normal de Santiago, Chile. Sobre la base de rasgos formales y decorativos de la alfareria, se realiza una adscripción estilistica de estas piezas. Adicionalmente, se entrega información contextual y bioantropológica sobre los entierros. Finalmente, se discuten temáticas relacionadas con la escala y naturaleza de la presencia Incaica en la cuenca de Maipo-Mapocho, y su relación con las poblaciones locales.

Palabras clave: Tawantinsuyu, Alfareria Inca, cultura Aconcagua, dinámicas de aculturación.

\section{Abstract}

This paper provides information about 17 ceramic vessels, which are part of the offerings from seven burials of the Inca Period, found at the site Estación Intermodal Quinta Normal de Santiago (Chile). Based on morphologic and decorative attributes we make a stylistic classification of the vessels. Additionally contextual and bioanthropological information of the burials is presented. Finally, we discuss topics related to the nature and scale of the Inca presence in the Maipo-Mapocho basin and its relationship with local groups.

Key words:Tawantinsuyu, Inca pottery, Aconcagua culture, cultural dynamics.

1 Licenciada en Antropología mención Arqueología. E-mail: kusvetiver@gmail.com

2 Licenciado en Antropología mención Arqueología. E-mail: fjabm@yahoo.com.

3 Arqueólogo. Departamento de Antropología Universidad de Chile. Ignacio Carrera Pinto 1045, Nuñoa, Santiago. E-mail: mur@uchile.cl

4 Licenciada en Antropología mención Arqueología. E-mail: solervi@yahoo.com

Recibido: Mayo 2008. Aceptado: Noviembre 2008. 


\section{INTRODUCCIÓN}

Una parte de la investigación en torno al Estado Inca y la naturaleza de su expansión se ha constituido a partir de los trabajos de Rowe (1945), Zuidema (1964), Wachtel (1973), Murra (1975) y Rostworowski (1988), quienes han trabajado temas de cronología, organización política, económica y territorial sobre la base de documentación histórica comparada en menor medida, con información de contextos arqueológicos. Esta mirada más conservadora de la sociedad Incaica y su expansión, asume que aproximadamente hacia el año 1476, es cuando se inicia el Horizonte Tardío, momento en el que se produce la anexión de la región de Ica al Tawantinsuyu. De esta manera se configuraría una corta cronología en donde el desarrollo y expansión del Incario se habría llevado a cabo en 70 años aproximadamente.

Por su parte, los autores que han tratado el tema centrados en una perspectiva más arqueológica (Raffino 1981 y 1993, Williams y D’Altroy 1998, D’Altroy 1992 y 2003, Stehberg 1995, Bauer 1996, Williams 2004, Uribe 1999-2000) desarrollada a partir de la excavación y análisis de sitios arqueológicos, se han abocado a la comprensión de los procesos de emergencia, expansión y dominación del territorio imperial, desde una perspectiva más localista, basados en tipología y cronologías absolutas. A partir de ello, en la porción sur del imperio se ha registrado una temprana presencia del Tawantinsuyu, que conllevó distintas etapas de desarrollo, evidenciándose una secuencia cronológica bastante más extensa que la propuesta desde la etnohistoria (1400 d.C.).

A partir de ello, el entendimiento de las dinámicas sociales generadas por la presencia Incaica en Chile Central a nivel político, económico e ideológico requiere la observación de la organización existente en la cultura material. En el contexto de la intervención estatal del Tawantinsuyu, los estudios en cerámica han sido relevantes a la hora de generar interpretaciones respecto a la interacción social con las poblaciones locales Aconcagua, las que configuran la unidad cultural arqueológica del período agroalfarero tardío. 


\section{Antecedentes}

Diversos autores han señalado que Chile Central se constituye como un área periférica del imperio, marginal al resto del territorio donde el dominio ha sido considerado como fragmentario y discontinuo (Raffino y Stehberg 1997, González 2000, Sánchez 2004), donde es posible encontrar sitios Incaicos de características variables, incluyéndose tramos del camino Inca, enclaves de extracción y producción de recursos locales, especialmente metalurgia, como el caso del asentamiento de funcionalidad multivariada de Cerro La Cruz (González 2000) y fortalezas como Mercachas, Chena y Cerro Grande de La Compañía. Se hipotetiza una zona muy poblada en el curso medio del Mapocho, evidenciada por la existencia de variantes de la red vial, acequias para agricultura y una cantidad considerable de cementerios; en cambio más al sur serían representativos los asentamientos defensivos constituidos por recintos amurallados en altura relacionados a la red vial (Stehberg 1976).

Los cementerios registrados en la cuenca Maipo-Mapocho presentan vínculos estilísticos diferentes entre sí, en relación a los contextos funerarios y el ofertorio de piezas involucradas. Por un lado tenemos el caso del cementerio de bóvedas de La Reina (Mostny 1947), donde se encontraron tumbas que se considera pertenecieron a individuos de la élite Incaica, con cámaras funerarias y ajuares con mayor presencia de objetos de estilo incaico. Es decir, un contexto Incaico de características más puras. Por otro lado, encontramos cementerios de otra naturaleza, tal es el caso de Nos (Stehberg 1976) y Las Tinajas de Quilicura (Baudet 2002), que hablan de una mayor interacción con la población local, donde la materialidad refleja expresiones Inca-Diaguita, a la vez que una presencia de alfarería Aconcagua de la Fase Inca. Y ya en Plaza Italia, Marcoleta y Compañía (Uribe 1999-2000) es posible evidenciar más bien alfarería Inca-Aconcagua.

Se sugiere que estos distintos cementerios podrían estar vinculados a diferentes sistemas de asentamientos, con disímiles grados de intervención Inca en el panorama local. La influencia incaica ha sido abordada a través del análisis del comportamiento de la cerámica presente en estos variados sitios y conjuntos de sitios. Los análisis estilísticos hablan en general de la presencia Inca-Diaguita en el contexto de un proceso de integración y aculturación por parte de la población Aconcagua, donde el elemento incaico se vería mediatizado por grupos foráneos diaguitas (González 2000, Cornejo 2001, Sánchez 2003). 
En general se ha considerado que el Inca impone sus patrones culturales relegando los de origen local a un estado de subordinación, sin la eliminación total de estos últimos. Desde la cerámica algunos autores han visto esto reflejado en la utilización de las formas incaicas, con variaciones relacionadas más bien a la decoración, donde patrones tales como la división cuatripartita del mundo, se fusionan con las estructuras y motivos locales (Cornejo 2001, Cantarutti y Mera 2002). Sin embargo es posible dar cuenta de situaciones donde se generarían articulaciones de forma y diseño locales y foráneas que implican motivos y modalidades novedosas, sin referentes previos al contacto con el Inca; tal sería el caso de algunas makas (aríbalos), categoría de vasija netamente incaica, cuyos rasgos generales son tomados y luego modificados (Sanhueza 2001), observándose así situaciones disímiles respecto a la influencia Inca y la reacción local hacia ella.

Las correlaciones estilístico-decorativas observadas en la cerámica existente entre el Pukara de Chena y los cementerios de San Agustín de Tango y Nos, han permitido hablar de un hipotético sistema de asentamiento Nos-Chena, que habría funcionado bajo un mismo esquema de producción especializada (Stehberg 1976). Aquí se observa la readaptación y transformación de las formas y diseños cuzqueńos hacia una realidad regional, con la existencia de copias locales "burdas" sin claro conocimiento del significado de algunos motivos cuzqueños, lo que lleva a plantear que la población nativa habría sufrido una aculturación rápida y superficial, manteniéndose patrones culturales más profundos como los son los vinculados al uso de cerámica utilitaria (jarros y ollas).

Algo similar se ha planteado para la relación existente entre la fortaleza de Chada y los sitios habitacionales de actividad agrícola Las Turbinas 1 y 2 en la zona de Angostura de Paine, estos dos últimos de filiación Aconcagua. La coexistencia de cerámica Inca-Diaguita y Aconcagua en la fortaleza, relacionada a las características de los sitios habitacionales y las óptimas condiciones del valle llevan a plantear un sistema de producción agrícola basado en la mano de obra local con funciones de abastecimiento y control territorial. Sin embargo la presencia efímera de ambos tipos cerámicos en las estructuras de vigilancia sugiere para los autores que esta coexistencia se debe a un corto período de aculturación, donde no se habría alcanzado una real imposición de los elementos Inca-Diaguitas sobre la alfarería local (Planella y Stehberg 1997). 
Así a partir del registro material se observaría una situación heterogénea y variable para la presencia incaica en la zona, lo que se ha interpretado como producto de diferentes relaciones sociopolíticas generadas con las poblaciones locales. Esta interacción adquiriría pautas locales debido a que las autoridades no habrían poseído dominio sobre grandes segmentos de la población (Sanhueza 2001). Esto lleva a plantear que los grupos Aconcagua no habrían sido asimilados totalmente y la participación dentro de las normativas incaicas se habría dado desde núcleos poblacionales específicos, por lo cual la presencia Inca adquiere un carácter discontinuo o difuso (Sánchez 2003).

Por otro lado se ha planteado que el Estado Inca controlaría local y regionalmente la fabricación de su cerámica empezando por las fuentes de materia prima, con una distribución selectiva a otras áreas en el contexto de estos núcleos de dominio discontinuo. Por ejemplo, desde una perspectiva tecno-funcional se sugiere un sistema de producción, uso y redistribución especializado de cerámica dentro del área Nos-Chena (Vásquez 1994). La homogeneidad observada en el uso y la elaboración de las pastas de la fragmentería del Pukará de Chena, junto a las evidencias estilístico-decorativas entre esta fortaleza y los cementerios asociados, indicarían una producción local con un origen areal de la materia prima.

La articulación de cerros-fortalezas y cementerios a modo de centros administrativos generaría sistemas de asentamiento que funcionarían como focos de la lógica expansiva del Tawantinsuyu, revelando una ocupación desigual y discontinua por parte de éste. Los grupos Aconcagua manifestarían una asimilación diferencial que se ha interpretado como dependiendo del grado de resistencia a la conquista (González 2000) o como un fenómeno de interdigitación cultural donde prima la interacción entre los grupos más que una aculturación o incaización plena de lo local. Esto se basa en la noción de que el dominio incaico, al ser mediatizado por la cultura Diaguita, estaría aprovechando las relaciones previas de ésta con la cultura Aconcagua (Sánchez 2004).

La hipótesis de un control discontinuo del espacio, llevado a cabo en distintos momentos y bajo diferentes estrategias de negociación con los locales (de acuerdo también a las características productivas y estratégicas de cada área) se vincula también a la idea de que los límites del imperio Inca son de difícil definición, ya que las fronteras políticas, económicas e ideológicas no necesariamente son coincidentes y poseen alcances variados (Dillehay y Gordon 1988, Williams 2004). Así, en el contexto de esta interacción social, 
son relevantes también las estrategias estatales de incorporación de los grupos locales al Tawantinsuyu, a través de mecanismos de eficacia simbólica. La presencia de santuarios de altura, como Cerro El Plomo (Mostny 1957) o Cerro Peladeros, donde el ritual de la capacocha acompaña actividades que habrían estado restringidas al manejo estatal, se enmarcan en un accionar simbólico-religioso. El camino Inca, símbolo del poder Incaico y articulador del paisaje local con el paisaje estatal, y las fortalezas como recordatorio constante de la presencia incaica, funcionarían dentro de un proceso de sacralización y apropiación cultural de nuevos dominios generando un nuevo "paisaje cultural". Desde esta perspectiva la población local es transculturada bajo la estrategia que reproduce el lugar de origen del "apropiador" (Uribe 1999-2000).

Así, en el proceso de incorporación de territorios lejanos, como en este caso, donde se sugiere una presencia de carácter más fragmentario y con estrategias variables de dominio (considerando lo observado en el norte del Ecuador, el oriente boliviano y el nor-oeste argentino), la cerámica se plantea como una expresión material de importancia, siendo la estandarización del estilo y de sus técnicas parte de las dinámicas operacionales de incorporación (Bray 2003). Con lo que la presencia de cerámica incaica o la existencia de distintos grados de influencia en la cerámica local, sugieren distintos niveles de relación con algún segmento de la red social y política del Estado (Cantarutti y Mera 2002).

\section{DESCRIPCIÓN DE LOS CONTEXTOS FUNERARIOS}

Particularmente, el cementerio -cuyas piezas se describen y analizan a continuación- fue excavado en una primera etapa hacia el año 2001 (Cantarutti y Mera 2002). Allí se rescataron cinco tumbas que contenían un ofertorio cerámico Diaguita-Inca y Aconcagua cronológicamente ubicados en el siglo XV (Tabla 1), dichos ofertorios presentaban concentraciones diferenciales, denotando unos, sólo elementos locales, y otros, características que vincularían a los individuos con una situación de privilegio dentro del Estado. De esta manera, los autores observan, a partir del estudio de estas 22 piezas, que se estaría frente a un contexto de producción que entrecruza rasgos de los diversos grupos en interacción.

En cuanto a la adscripción de los tipos decorativos y clases cerámicas, se consideró la clasificación previa propuesta por Cantarutti y Mera (2002) en este mismo cementerio. Con el propósito de darle continuidad al registro de la información rescatada previamente se ha considerado la estructura 
analítica y metodología de este último estudio. Sin embargo, a diferencia del trabajo del año 2002, fueron tomados en cuenta los trabajos bioantropológicos disponibles (Reyes et al. 2005, Leiva 2006), ayudando a generar una información más acabada del contexto de rescate de las ofrendas cerámicas detallada a continuación (Tabla 2). Cabe aclarar que la nomenclatura general de las tumbas se basó en la numeración existente para los entierros excavados en la campaña anterior (Reyes et al. 2005, Cantarutti y Mera 2002).

Tabla 1. Fechados por termoluminiscencia del sitio Cementerio Estación Quinta Normal (Reyes et al. 2005)

Table 1. Thermoluminiscence dates from Quinta Normal Station Cemetery site (Reyes et al. 2005).

\begin{tabular}{|l|l|l|}
\hline Tumba & Fecha & Material \\
\hline 1 & $1485+/-55$ d.C. & Escudilla Rojo Engobada \\
\hline 2 & $1500+/-50$ d.C. & Olla monocroma \\
\hline 3 & $1475+/-50$ d.C. & Olla monocroma \\
\hline 4 & $1470+/-50$ d.C. & Aríbalo \\
\hline 4 & $1485+/-55$ d.C. & Olla monocroma \\
\hline 5 & $1495+/-50$ d.C. & Jarro Pato Decorado \\
\hline 5 & $1405+/-60$ d.C. & Escudilla Decorada \\
\hline
\end{tabular}




\section{Tabla 2. Contextos funerarios según tumba}

Table 2. Funeral contexts by tomb

\begin{tabular}{|c|c|c|c|c|c|c|c|c|}
\hline $\begin{array}{l}\text { Tum- } \\
\text { ba }\end{array}$ & \begin{tabular}{|l|}
$\mathrm{N}^{\circ}$ \\
Indiv.
\end{tabular} & $\begin{array}{l}\text { Tipo } \\
\text { Entierro } \\
\end{array}$ & Sexo & Edad & $\begin{array}{l}\text { Orienta- } \\
\text { ción Fosa }\end{array}$ & Posición & Mirada & Ofrendas \\
\hline & & & & Subadulto & & Decúbito lateral & & \\
\hline 1 & 1 & Primario & Femenino & $\begin{array}{l}\text { entre } 15 \text { y } 20 \\
\text { ańos }\end{array}$ & $\mathrm{N} / \mathrm{O}$ & \begin{tabular}{|l} 
derecho \\
extendido
\end{tabular} & Norte & $\begin{array}{l}6 \text { vasijas } \\
\text { cerámicas }\end{array}$ \\
\hline & & & & Adulto & & Decúbito lateral & & \\
\hline 2 & 1 & Primario & Femenino & $\begin{array}{l}\text { entre } 20 \text { y } 30 \\
\text { ańos }\end{array}$ & $\mathrm{N} / \mathrm{O}$ & $\begin{array}{l}\text { derecho } \\
\text { extendido }\end{array}$ & Norte & $\begin{array}{l}1 \text { vasija } \\
\text { cerámica }\end{array}$ \\
\hline & & & & Adulto & & Decúbito dorsal & & \\
\hline 3 & 1 & Primario & Masculino & $\begin{array}{l}\text { mayor de } 20 \\
\text { años }\end{array}$ & $\mathrm{N} / \mathrm{O}$ & extendido & Arriba & $\begin{array}{l}4 \text { vasijas } \\
\text { cerámicas }\end{array}$ \\
\hline & & & & Adulto & & Decúbito dorsal & & \\
\hline 4 & 1 & Primario & Femenino & $\begin{array}{l}\text { entre } 20 \text { y } 25 \\
\text { ańos }\end{array}$ & SE-NW & extendido & Poniente & $\begin{array}{l}8 \text { vasijas } \\
\text { cerámicas }\end{array}$ \\
\hline & & & & Adulto & & Decúbito lateral & & \\
\hline 5 & 1 & Primario & Femenino & $\begin{array}{l}\text { entre } 25 \text { y } 35 \\
\text { ańos }\end{array}$ & $\mathrm{N} / \mathrm{O}$ & $\begin{array}{l}\text { derecho } \\
\text { extendido }\end{array}$ & Norte & $\begin{array}{l}3 \text { vasijas } \\
\text { cerámicas }\end{array}$ \\
\hline 6 & 1 & Primario & Femenino & Adulto & NE-SW & Decúbito lateral & Noroeste & \\
\hline & & & & $\begin{array}{l}\text { entre } 18 \text { y } 28 \\
\text { ańos }\end{array}$ & & \begin{tabular}{|l|} 
derecho \\
extendido
\end{tabular} & & $\begin{array}{l}4 \text { vasijas } \\
\text { cerámicas }\end{array}$ \\
\hline 7 & 1 & Primario & Indefinido & Infante & NW-SE & Decúbito lateral & Norte & \\
\hline & & & & $\begin{array}{l}\text { entre } 3 \text { y } 5 \\
\text { ańos }\end{array}$ & & \begin{tabular}{|l|} 
derecho \\
extendido
\end{tabular} & & $\begin{array}{l}2 \text { vasijas } \\
\text { cerámicas }\end{array}$ \\
\hline 8 & 2 & & Femenino & Adulto & NE-SW & $\begin{array}{l}\text { Decúbito } \\
\text { ventral }\end{array}$ & Norte & \\
\hline & & Primario & & $\begin{array}{l}\text { más de } 28 \\
\text { años }\end{array}$ & & $\begin{array}{l}\text { derecho } \\
\text { extendido }\end{array}$ & & $\begin{array}{l}3 \text { vasijas } \\
\text { cerámicas }\end{array}$ \\
\hline & & Múltiple & Indefinido & Infante 3 ańos & NE-SW & Decúbito lateral & Norte & $\begin{array}{l}\text { y cuentas de } \\
\text { collar }\end{array}$ \\
\hline & & & & & & $\begin{array}{l}\text { derecho } \\
\text { semiflectado }\end{array}$ & & \\
\hline 10 & 1 & Indeter- & Indefinido & Infante & Indeter- & Indeterminada & Indeter- & 1 vasija \\
\hline & & minado & & $\begin{array}{l}\text { entre } 4 \text { y } 6 \\
\text { ańos }\end{array}$ & minada & & minada & cerámica \\
\hline & & & & & & & & $\begin{array}{l}1 \text { vasija } \\
\text { cerámica }\end{array}$ \\
\hline 11 & 1 & $\begin{array}{l}\text { Indeter- } \\
\text { minado }\end{array}$ & Indefinido & $\begin{array}{l}\text { Indetermi- } \\
\text { nado }\end{array}$ & $\begin{array}{l}\text { Indeter- } \\
\text { minada }\end{array}$ & Indeterminada & $\begin{array}{l}\text { Indeter- } \\
\text { minada }\end{array}$ & $\begin{array}{l}\text { y cuentas de } \\
\text { collar }\end{array}$ \\
\hline 13 & 1 & Primario & Masculino & Adulto & N-S & Decúbito lateral & Sur & $\begin{array}{l}5 \text { vasijas } \\
\text { cerámicas }\end{array}$ \\
\hline & & & & $\begin{array}{l}\text { entre } 18 \text { y } 28 \\
\text { años }\end{array}$ & & $\begin{array}{l}\text { derecho } \\
\text { extendido }\end{array}$ & & $\begin{array}{l}\text { y } 2 \text { puntas } \\
\text { proyectil }\end{array}$ \\
\hline
\end{tabular}

Para la mayor parte de los entierros es posible discernir los límites de las fosas a partir de cambios en la matriz, como arena fina en las tumba 8 y 13. Algunas de ellas presentan además una hilera de cantos rodados y clastos al costado de los cuerpos a modo de apoyo para el dorso o simple- 
mente siguiendo la orientación del cuerpo, lo que sucede en las tumbas 6 y 7. Notorio es el caso de la tumba 13, donde se registra una posible bóveda relacionada con un cúmulo de bolones hacia Sur-Oeste de la fosa. Esta última presenta límites definidos por arena y arcilla sobre el estrato natural de bolones, donde fue directamente depositado el cuerpo del individuo masculino.

Otro rasgo interesante es la existencia de fibras vegetales en las tumbas 6 y 7 , que fueron interpretadas como remanentes de elementos textiles y cuerdas que podrían haber estado fijando las articulaciones de rodillas y tobillos manteniéndolos juntos, a modo de un fardo funerario. Se infiere que el individuo de la tumba 13 poseía una mortaja debido al hallazgo de fibras vegetales con urdimbre que envolvían el cuerpo. Esto también se aplica a una posible cobertura para los contenedores cerámicos depositados en dicha tumba, correlacionando el hecho de que se registraron restos de la extremidad de un camélido sobre el hombro izquierdo del individuo, aislados por restos de estas mismas fibras (Leiva 2006).

Las tumbas 10 y 11 no poseían buen estado de conservación, constituyéndose la primera únicamente de restos de cráneo encontrados bajo una escudilla asociada a tres clastos depositados en conjunto. La tumba 11, ubicada bajo el entierro 7 y separada de éste por 30 centímetros de sedimentos estériles, poseía una fosa con límites claros, pero sólo se encontraron algunos dientes humanos asociados a espículas de carbón y cinco semillas directamente relacionadas a la ofrenda cerámica (Leiva 2006).

La disposición de las ofrendas cerámicas se observa al costado de los cuerpos o junto al cráneo de los individuos. En la tumba 13 éstas se encuentran alineadas de mayor a menor a lo largo del costado izquierdo del cuerpo. Cuentas de collar se registraron in situ como ajuar funerario asociadas al cráneo del infante de la tumba 8; éste había sido depositado sobre el dorso del individuo femenino, con la cabeza apoyada en la región glútea (Leiva 2006).

\section{Tumba 6:}

Vasija no ${ }^{5}$ : Depositado cerca del cráneo del individuo se registró un aríbalo, cuya superficie exterior, engobada y pulida, exhibe un color blanco en el cuello y rojo en todo el cuerpo. La superficie interior también se encuentra engobada y pulida, pero sólo hasta la altura del amplio borde de

5 Para la descripción de cada una de las piezas remitirse a Tablas 3 y 4, además de Figura 1. 
la vasija, estando el resto del cuerpo alisado y espatulado (Figura 1 y 2). En general destaca la irregularidad de su manufactura, en comparación con el otro aríbalo correspondiente al individuo de la tumba $n^{\circ} 13$. La pieza aquí descrita denota una fuerte erosión en el perímetro de la base, junto a piquetes y rasmilladuras en el cuerpo inferior. Muestra, además, adherencias posiblemente producto de la exposición directa o indirecta al fuego.

Vasija n²: Consiste en un jarro colocado junto al cráneo del individuo en el extremo Este de la tumba. No posee decoración, la superficie es de color marrón y se encuentra alisada tanto por dentro como por fuera, donde el tratamiento es en general tosco. Esta pieza posee ahumado y hollín en toda la base y sección frontal del cuello y cuerpo (zona opuesta al asa). También se registran diversas rasmilladuras y piqueteos en la zona de la base.

Vasija no3: Corresponde a un puco ${ }^{6}$ que fue ubicado a la altura del tórax del individuo, hacia el norte de éste. La superficie exterior se encuentra pulida y engobada de rojo, lo mismo sucede en el interior, pero aquí el puco presenta una banda perimetral en el borde y una cruz diametral llevada a cabo con el mismo pigmento rojo sobre el fondo natural, lo que genera una configuración cuatripartita. En la superficie externa es posible observar la presencia de ahumado y hollín.

Vasija no4: Colocada junto a los pies del individuo, en el extremo oeste de la tumba, se encuentra una olla. Esta pieza, completamente alisada, posee una coloración café rojiza en el exterior y en el interior la superficie es café anaranjada. No posee decoración. Presenta hollín y ahumado prácticamente en toda la superficie exterior, no así en la base, la cual exhibe erosión (zona de apoyo).

6 Entendemos por puco todas aquellas piezas de perfil simple, no restringidas y de paredes altas, cuyas proporciones altura/diámetro deben ser iguales o menores que 1:2,9. Se diferencia del cuenco, ya que éste, a pesar de poseer un contorno simple, consiste en una vasija restringida, es decir, presenta la inversión de sus bordes. La escudilla, en cambio, siendo una forma no restringida, se diferencia del puco al no presentar paredes altas y por tener un borde directo o abierto, en una proporción altura/diámetro igual o mayor a 1:3. 


\section{Tabla 3. Vasijas cerámicas y atributos morfológicos del sitio Cementerio Estación Quinta Normal}

Table 3. Pottery vessels and morphologic attributes from Quinta Normal Station Cemetery site

\begin{tabular}{|c|c|c|c|c|c|c|c|c|}
\hline $\begin{array}{l}\text { Tum- } \\
\text { ba }\end{array}$ & \begin{tabular}{|l|} 
Va- \\
sija \\
\end{tabular} & \begin{tabular}{l|} 
Tipo de \\
Artef.
\end{tabular} & \begin{tabular}{|l|} 
Tipo \\
Borde
\end{tabular} & $\begin{array}{l}\text { Tipo } \\
\text { Labio }\end{array}$ & $\begin{array}{l}\text { Forma } \\
\text { Cuello }\end{array}$ & \begin{tabular}{|l|} 
Forma \\
Cuerpo
\end{tabular} & \begin{tabular}{|l|} 
Tipo \\
Base
\end{tabular} & Asas \\
\hline 6 & 1 & Aríbalo & Evertido & Convexo & $\begin{array}{l}\text { Hiper- } \\
\text { boloide }\end{array}$ & \begin{tabular}{|l|} 
Ovoide \\
Invertido
\end{tabular} & Cóncava & $\begin{array}{l}\text { Dos asas verticales en arco } \\
\text { de correa, emplazadas en el } \\
\text { cuerpo medio }\end{array}$ \\
\hline 6 & 2 & Jarro & Directo & Convexo & $\begin{array}{l}\text { Cónico } \\
\text { Inverti- } \\
\text { do }\end{array}$ & Ovoide & Plana & $\begin{array}{l}\text { Asa vertical en arco de } \\
\text { correa, emplazada de } \\
\text { labio (adherida) a cuerpo } \\
\text { (remachada) }\end{array}$ \\
\hline 6 & 3 & Puco & Directo & Convexo & 1 & Subelíptica & Convexa & 1 \\
\hline 6 & 4 & Olla & Evertido & Convexo & $\begin{array}{l}\text { Hiper- } \\
\text { boloide }\end{array}$ & Ovoide & \begin{tabular}{|l|} 
Plano- \\
convexa
\end{tabular} & $\begin{array}{l}\text { En arco de correa, } \\
\text { verticales. Adheridas en } \\
\text { ambos extremos (una } \\
\text { ausente). }\end{array}$ \\
\hline 7 & 1 & Plato & Directo & $\begin{array}{l}\text { Plano- } \\
\text { convexo }\end{array}$ & 1 & Subelíptica & Convexa & $\begin{array}{l}\text { Asa horizontal en arco de } \\
\text { correa, adherida en ambos } \\
\text { puntos de unión al labio }\end{array}$ \\
\hline 7 & 2 & Cuenco & Invertido & $\begin{array}{l}\text { Plano- } \\
\text { convexo }\end{array}$ & 1 & Subelíptica & Convexa & 1 \\
\hline 8 & 1 & Jarro & Evertido & Convexo & $\begin{array}{l}\text { Hiper- } \\
\text { boloide }\end{array}$ & Ovoide & Convexa & $\begin{array}{l}\text { Asa vertical en arco } \\
\text { de correa; adherida y } \\
\text { remachada en el extremo } \\
\text { inferior. }\end{array}$ \\
\hline 8 & 2 & Puco & Directo & Plano & 1 & \begin{tabular}{|l|} 
Cónico \\
Invertido
\end{tabular} & $\begin{array}{l}\begin{array}{l}\text { Plano- } \\
\text { cóncava }\end{array} \\
\end{array}$ & I \\
\hline 8 & 3 & Cuenco & \begin{tabular}{|l|} 
Lev. \\
Evertido
\end{tabular} & Plano & $\begin{array}{l}\text { Cilín- } \\
\text { drico }\end{array}$ & Subelíptica & Convexa & 1 \\
\hline 10 & 1 & Plato & Directo & $\begin{array}{l}\text { Plano- } \\
\text { convexo }\end{array}$ & 1 & Subesférico & Convexa & 1 \\
\hline 11 & 1 & Cuenco & Invertido & Convexo & 1 & Subelíptica & Convexa & 1 \\
\hline 13 & 1 & Jarro & Evertido & Convexo & $\begin{array}{l}\text { Hiper- } \\
\text { boloide }\end{array}$ & Ovoide & Convexa & $\begin{array}{l}\text { Asa vertical tipo cinta, } \\
\text { de sección subelíptica, } \\
\text { emplazada sobre el labio y } \\
\text { unión cuello-cuerpo }\end{array}$ \\
\hline 13 & 2 & Olla & Evertido & Convexo & $\begin{array}{l}\text { Hiper- } \\
\text { boloide }\end{array}$ & Subelíptica & Convexa & $\begin{array}{l}\text { Dos asas en arco de correa, } \\
\text { verticales, de sección } \\
\text { elipsoidal, levemente } \\
\text { acanaladas }\end{array}$ \\
\hline 13 & 3 & Aríbalo & Evertido & Convexo & $\begin{array}{l}\text { Hiper- } \\
\text { boloide }\end{array}$ & $\begin{array}{l}\text { Ovoide } \\
\text { Apuntado }\end{array}$ & Cóncava & $\begin{array}{l}\text { Dos asas cinta en posición } \\
\text { vertical, emplazadas a la } \\
\text { altura del cuerpo medio }\end{array}$ \\
\hline 13 & 4 & Botella & Evertido & n.p. & $\begin{array}{l}\text { Hiper- } \\
\text { boloide }\end{array}$ & Subesférico & $\begin{array}{l}\begin{array}{l}\text { Plano- } \\
\text { convexa }\end{array} \\
\end{array}$ & 1 \\
\hline 13 & 5 & Plato & Invertido & Convexo & 1 & Subelíptica & Convexa & 1 \\
\hline
\end{tabular}




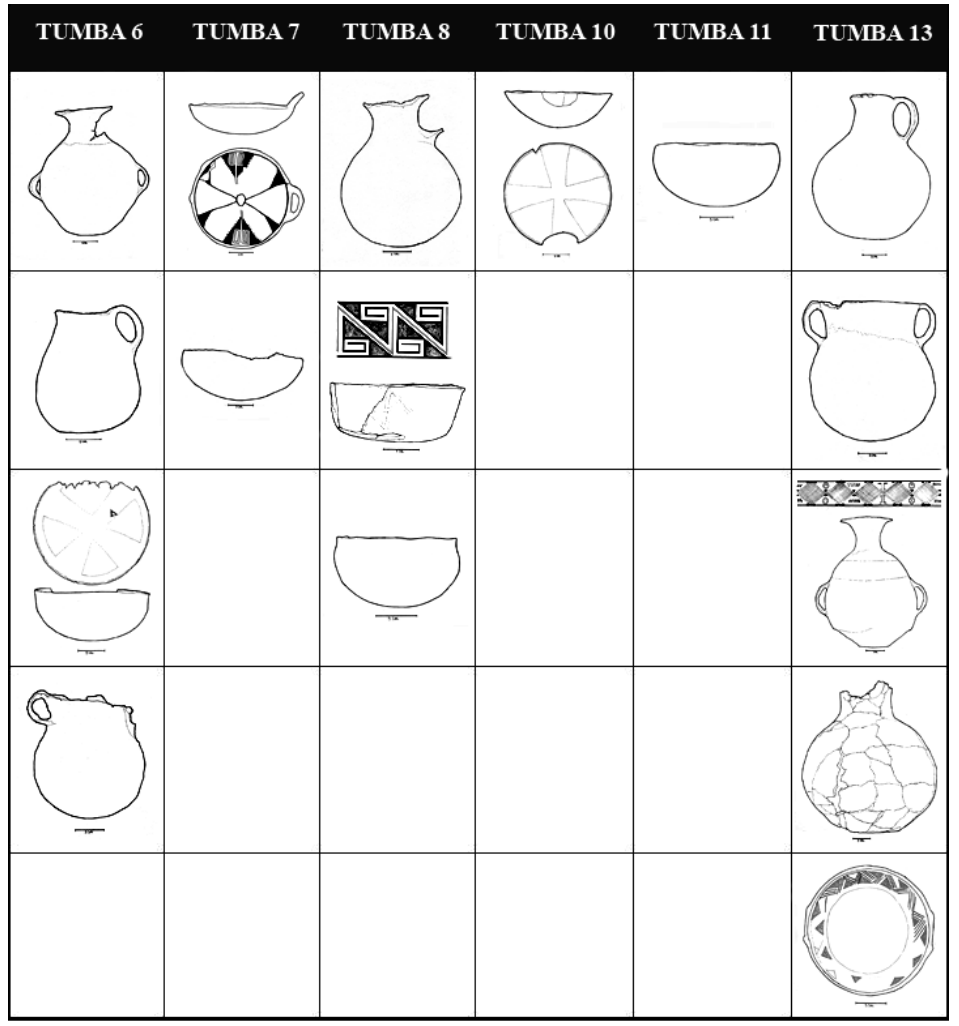

Figura 1: Cuadro vasijas por tumbas. Escala $=5 \mathrm{~cm}$.

Figure 1: Image of vessels by tombs. Scale: $5 \mathrm{~cm}$.

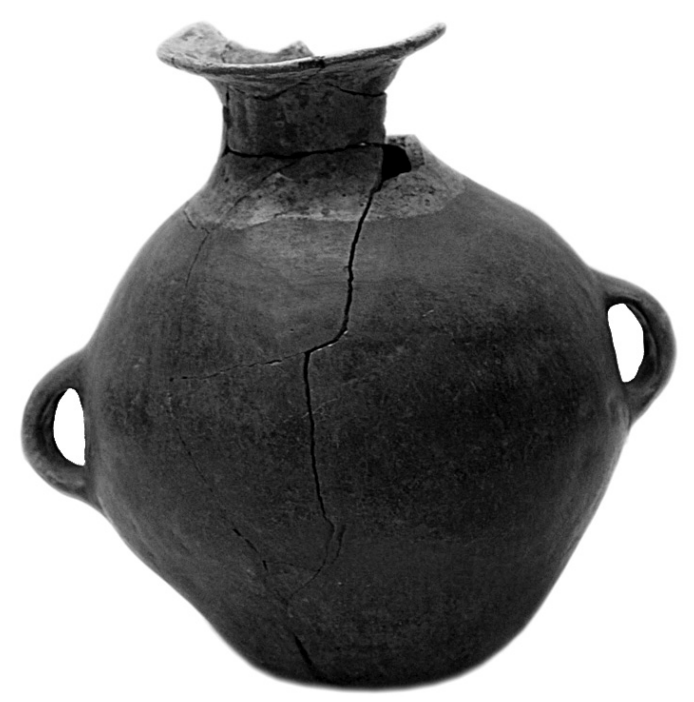

Figura 2: Aríbalo Rojo y Blanco, Tumba 6 Vasija 1

Figure 2: Red and white aribalo, tomb 6, vessel 1. 
Tabla 4. Vasijas del sitio Cementerio Estación Quinta Normal y sus atributos métricos $\left({ }^{*}=\right.$ alturas parciales $)$

Table 4. Vessels from the Quinta Normal Station Cemetery site and their metric attributes $\left(^{*}=\right.$ partial heights)

\begin{tabular}{|llllllllllll|}
\hline & $\begin{array}{l}\text { Tipo de } \\
\text { Artef. }\end{array}$ & $\begin{array}{l}\text { Alt. } \\
\text { Total } \\
(\mathrm{mm})\end{array}$ & $\begin{array}{l}\text { Diam. } \\
\text { Cuerpo } \\
(\mathrm{mm})\end{array}$ & $\begin{array}{l}\text { Diam. } \\
\text { Borde } \\
(\mathrm{mm})\end{array}$ & $\begin{array}{l}\text { Alt. } \\
\text { Cuello } \\
(\mathrm{mm})\end{array}$ & $\begin{array}{l}\text { Diam. } \\
\text { Base } \\
(\mathrm{mm})\end{array}$ & $\begin{array}{l}\text { Gar- } \\
\text { ganta } \\
(\mathrm{mm})\end{array}$ & $\begin{array}{l}\text { Esp. } \\
\text { Pared } \\
(\mathrm{mm})\end{array}$ & $\begin{array}{l}\text { Vol. } \\
(\mathrm{cc})\end{array}$ & $\begin{array}{l}\text { Peso } \\
(\mathrm{gr})\end{array}$ \\
6 & 1 & Aríbalo & 294 & 240 & 130 & 64 & 98 & 98 & 6 & 6550 & 2900 \\
6 & 2 & Jarro & 123 & 114 & 59 & 38 & 74 & 80 & 4,7 & 750 & 414 \\
6 & 3 & Puco & 77 & 180 & 180 & $/$ & n.d. & $/$ & 5 & 1300 & 409 \\
6 & 4 & Olla & 174 & 164 & 145 & 36 & 69 & 122 & 6 & 2400 & 945 \\
7 & 1 & Plato & 47 & 188 & 188 & $/$ & n.d. & $/$ & 5 & 800 & 324 \\
7 & 2 & Cuenco & 71 & 176 & 171 & $/$ & n.d. & $/$ & 5 & 1200 & 343 \\
8 & 1 & Jarro & $270 *$ & 105 & n.p. & $77 *$ & n.d. & 100 & 5,3 & 5500 & 2200 \\
8 & 2 & Puco & 160 & 64 & 64 & $/$ & 136 & $/$ & 6,5 & 900 & 374 \\
8 & 3 & Cuenco & 96 & 161 & 152 & $/$ & n.d. & $/$ & 4,7 & 1450 & 489 \\
10 & 1 & Plato & 82 & 250 & 250 & $/$ & n.d. & $/$ & 4 & 2400 & 533 \\
11 & 1 & Cuenco & 65 & 135 & 133 & $/$ & n.d. & $/$ & 4 & 700 & 247 \\
13 & 1 & Jarro & 278 & 237 & 106 & 87 & n.d. & 106 & 5,2 & 6450 & 2100 \\
13 & 2 & Olla & 261 & 255 & 220 & 67 & n.d. & 190 & 6,8 & 9200 & 2700 \\
13 & 3 & Aríbalo & 409 & 287 & 152 & 86 & 86 & 91 & 6 & 14500 & 3200 \\
13 & 4 & Botella & $448 *$ & 357 & n.p. & $113 *$ & 121 & 189 & 8 & 28000 & 6800 \\
13 & 5 & Plato & 46 & 175 & 171 & $/$ & n.d. & $/$ & 5 & 700 & 375 \\
\hline
\end{tabular}

\section{Tumba 7:}

Vasija no ${ }^{\circ}$ : Consiste en un plato que fue depositado junto al sector donde se ubicaba el cráneo del individuo (sólo se registraron los dientes), hacia el extremo este de la tumba. Esta forma es adscribible al plato plano tipo A definido por González (González 1995), el cual presenta un asa en forma de arco horizontal y en el borde opuesto, dos protuberancias cercanas entre sí. Toda la superficie se encuentra pulida y engobada de rojo, en el interior se encuentra además decorada con pintura negra. Esta decoración, de origen Diaguita, presenta un motivo constituido por cuatro líneas que parten de triángulos rectángulos rellenos ubicados junto al borde de la pieza, las que convergen hacia un centro definido por el delineado de un círculo. Cada par de líneas se disponen en lados opuestos en el plano del diseño. En sentido perpendicular se observa otro motivo que consiste en dos triángulos con pestañas con greca incluida que se reflejan y posteriormente se oponen a otro par idéntico en el otro extremo del plato. Ambos pares de triángulos 
proyectan dos líneas paralelas, unidas en sus extremos, que se orientan hacia el centro donde se ubica el círculo. El plano general de la disposición de estos motivos se configura de forma hexagonal y se encuentra delimitado por una línea perimetral al interior del labio. Sobre el asa se registra una línea que corre por el costado del asa traspasando la unión con el labio del plato. Por otro lado presenta dos protúberos adheridos al labio en la sección opuesta al asa. Se encuentran separados por $40 \mathrm{~mm}$ y también fueron pintados de negro. Hay que señalar que esta oposición al asa no es simétrica del todo.

Manifiesta también huellas de uso previo, observándose leve erosión en la base y salpicaduras del engobe en varias zonas del cuerpo, en especial hacia el interior en el centro del plato.

Vasija no2: Corresponde a un cuenco ubicado en el extremo oeste de la tumba, en lo que habría sido el sector de los pies del individuo. Este se encuentra completamente engobado de rojo, estando pulido al interior y bruñido al exterior.

Presenta ahumado en prácticamente toda la superficie exterior. Posee pequeñas zonas con abrasión en el interior. El punto de apoyo de la base se encuentra levemente erosionado y se observa piqueteo en el labio, así como fracturas antiguas en dos sectores del borde.

\section{Tumba 8:}

Vasija $\mathrm{n}^{\circ}$ 1: Se trata de un jarro que fue depositado, junto con otras vasijas, detrás del cráneo del individuo. Esta pieza está pulida y engobada de rojo en exterior, lo que también se registra en el interior, exclusivamente en el cuello del jarro.

Presenta huellas de uso claras en el cuerpo inferior, allí la superficie se observa muy erosionada. El cuello inferior interno presenta salpicaduras posiblemente por golpeteo. Las fracturas antiguas que posee éste también se deducen del uso.

Vasija no2: Consiste en un puco que hace parte del conjunto de vasijas depositadas detrás del cráneo del individuo. Se asemeja a la variedad C propuesta para esta categoría de vasijas por González, señalando que se trata de piezas de paredes más bajas que los otros pucos, de base ancha y semiplana (González 1995) (Figura 3). La superficie interior de la pieza se encuentra pulida y engobada de blanco. En el cuerpo exterior también presenta estas características, no así la base que al parecer bajo las huellas de exposición al 
fuego, muestra un baño de engobe rojo. Sobre este revestimiento presenta decoración pintada en negro y rojo que combina motivos que generan el patrón zig-zag adscribible al tipo C de González (1995, 2004). Este diseño decorativo se construye a partir de la combinación de los motivos de grecas, triángulos escalerados opuestos, líneas paralelas horizontales, verticales y diagonales que se distribuyen en 10 campos.
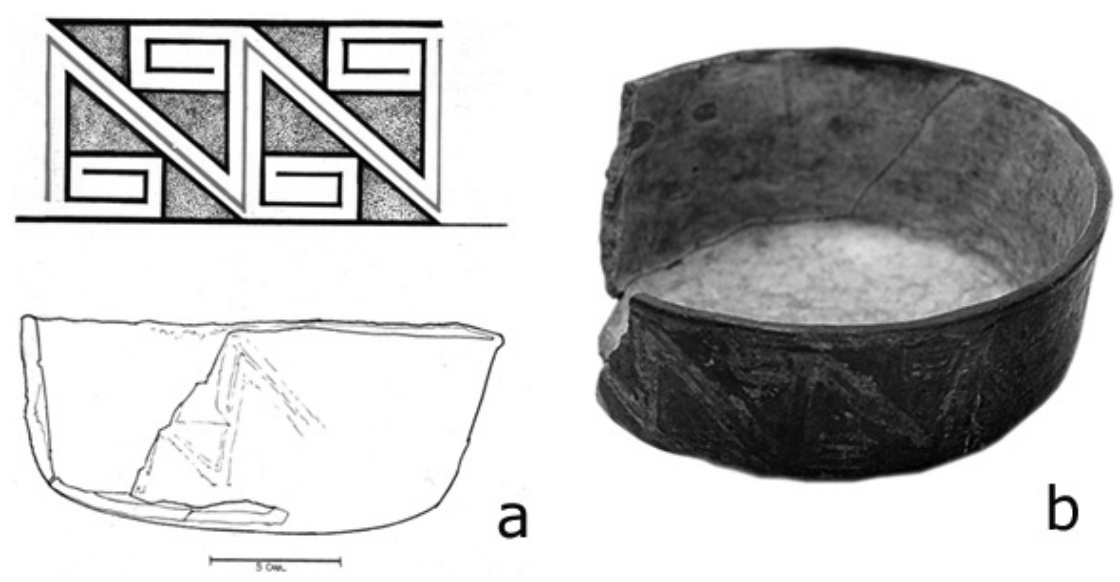

Figura 3: Patrón Zig-Zag B, Tumba 8 Vasija 2

Figure 3: Zig-Zag pattern B, tomb 8, vessel 2.

Este puco presenta gran cantidad de ahumado y hollín en el cuerpo y la base exterior, a tal punto de hacer difícil la observación del tratamiento de superficie y decoración. También se observan descascaramientos o salpicaduras del esmalte, principalmente al interior.

Vasija no3: Corresponde a un cuenco registrado adyacente al occipital del individuo. La superficie exterior se observa pulida y engobada de rojo, el interior de la pieza está pulido, pero posee engobe del mismo color sólo en el borde. No se observan claras huellas de uso.

\section{Tumba 10':}

Vasija no1: Esta escudilla fue rescatada junto al cráneo del individuo. Hacia el exterior se encuentra pulida y engobada de rojo, presentando además, leves huellas de erosión en el punto de apoyo de la base y el perímetro

\footnotetext{
7 La tumba 9 corresponde a un entierro que posee una olla del tipo Inciso Reticulado Oblicuo sin decoración ni modelados, asignada al Período Alfarero Temprano, más específicamente a la tradición Llolleo (Sanhueza y Latorre 2006). Dicha pieza no se considera en el presente escrito, sin embargo es posible encontrar una descripción completa en el Informe de análisis cerámico: Las vasijas completas del sitio Estación Intermodal Quinta Normal.
} 
del labio. En tanto, la superficie interna se encuentra pulida y pintada de rojo, exhibiendo dos gruesas líneas perpendiculares que se cruzan en el centro en ángulo recto, cuatripartiendo la pieza. Se registran pequeños residuos dispersos en el interior y exterior, posiblemente hollín.

\section{Tumba 11:}

Vasija $n^{\circ} 1$ : Se trata de un cuenco que se ubicaba en el centro de la fosa donde sólo fueron rescatados restos dentales. Tanto la superficie externa como la interna se encuentran engobadas de rojo y pulidas. La cara externa presenta erosión y descascaramiento en el perímetro de apoyo del cuerpo inferior.

\section{Tumba $13^{8}$ :}

Vasija no ${ }^{\circ}$ : Consiste en un jarro que se disponía a los pies del individuo en el extremo norte de la fosa. Este se encuentra pulido y engobado de rojo en el exterior y en el borde interior (Figura 4). Tanto el cuerpo inferior como el labio presentan erosión por uso. Si bien la vasija se presenta completa, fue "matada", pues exhibe un agujero intencional en el cuerpo superior (16 mm. diámetro), además de dos profundas raspaduras en el labio realizadas con un instrumento cortante y/o abrasivo.

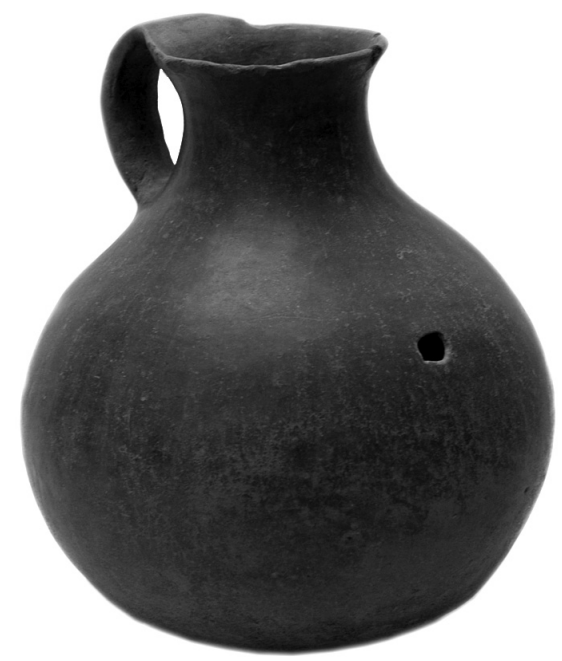

Figura 4: Jarro Rojo Engobado, Tumba 13 Vasija 1

Figure 4: Red painted jug, tomb 13, vessel 1

8 La tumba 12 corresponde a un entierro sin ofertorio cerámico. 
Vasija no2: Corresponde a una olla que se ubicaba junto a la tibia izquierda del individuo, en la alineación norte-sur de vasijas ofrendadas. La pieza se encuentra completamente alisada y su aspecto presenta variaciones de color café marrón. Huellas de uso producto de actividades domésticas, como el ahumado y el hollín, se manifiestan en la pared externa en todo el cuerpo, mientras que la base se encuentra muy erosionada, evidenciando una alta abrasión.

Vasija no3: Trata de un aríbalo que se encontraba a la altura de la pelvis del individuo, en el centro de la alineación de cántaros del entierro. El cuello y la parte superior del cuerpo evidencian una superficie externa engobada de rojo, pulida y con decoración pintada de color negro, rojo y blanco. Esta consiste en una banda de rombos rellenos de reticulados oblicuos, cuyos negativos forman triángulos que se reflejan y forman pares de círculos concéntricos, rectángulos rellenos con pestañas y líneas perpendiculares formando ángulos rectos, evocando quizás de manera abstracta motivos zoo antropomorfos (Troncoso 2005), recordando el motivo del felino expresado en la cultura Diaguita. Por otra parte el cuerpo inferior sólo se encuentra pulido sin ningún tipo de revestimiento, evidenciando también erosión y huellas de ahumado. La superficie interna a su vez, exhibe pintura negra sobre engobe blanco en el borde, en las mismas tonalidades que la pared externa, denotando líneas perpendiculares que forman ángulos rectos reflejados. Esta decoración también se presenta en aríbalos y platos planos Inca Mixtos del área Diaguita (Cantarutti 2002: 212), lo cual refuerza la idea de conexiones estilísticas con dicha tradición en la pieza descrita. En tanto, el resto del cuello y el cuerpo presentan superficies alisadas.

Esta pieza exhibe erosión en el perímetro de la base y cuerpo inferior. Muestra algo de salpicaduras del engobe en la zona media del cuerpo. Por otro lado, en ciertas zonas de la superficie interior se observan descascaramientos y una leve mancha oscura en la base.

Vasija no4: Consiste en una botella de grandes proporciones, que se encontraba junto al brazo izquierdo del individuo. Tanto la superficie exterior como la interior fueron alisadas, denotando tonos de color café. Presenta huellas de hollín en gran parte del cuerpo exterior y una intensa abrasión en la base y cuerpo inferior interno.

Vasija $\mathrm{n}^{\circ} 5:$ Se trata de un plato que se ubicaba sobre la vasija $\mathrm{n}^{\circ} 4$, adyacente a la zona del abdomen del individuo. Presenta dos pares de protúberos opuestos adheridos al labio. Este último rasgo, se asocia a los platos planos de Forma B propuesta por González (1995), definidos por no presentar asa, sino dos pares de protuberancias en el borde, opuestas entre sí (Figura 
5). La superficie exterior se encuentra engobada de rojo y pulida, denotando ciertas huellas de hollín y erosión cerca de la base. La superficie interna en tanto, está pulida y pintada negro, rojo y blanco, carece de engobe rojo y se encuentra levemente erosionada en el centro.

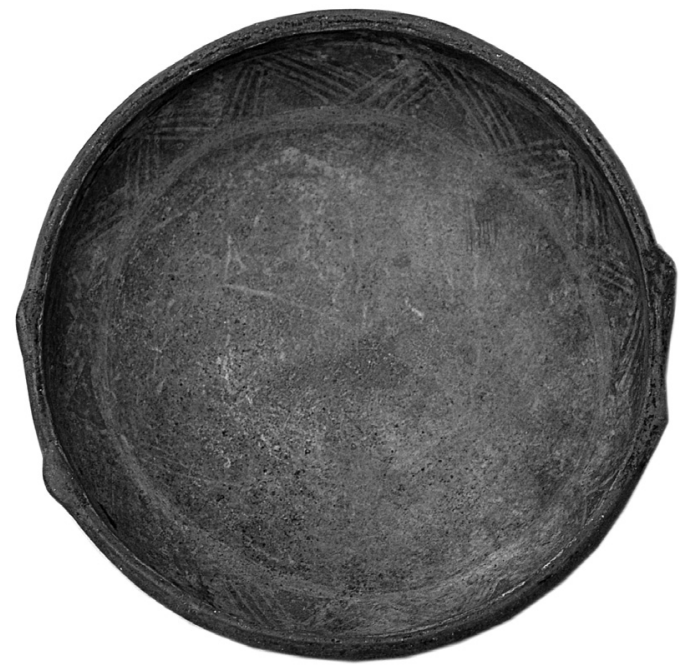

Figura 5: Plato plano, Tumba 13 Vasija 5

Figure 5: Flat plate, tomb 13, vessel 5

La decoración consta de una banda anular estrecha que en su interior presenta líneas diagonales cortas separadas y triángulos negros en negativo, formando un patrón zig-zag, asociado a expresiones de la cultura Diaguita (Cantarutti y Mera 2002).

\section{ANÁLISIS ESTILÍSTICO Y CLASIFICACIÓN DE LA ALFARERÍA}

Este estudio y análisis estilístico se basa en la clasificación propuesta por Calderari y Williams (1991) que fue aplicada al contexto Incaico de la cuenca del Maipo-Mapocho por Cantarutti y Mera (2002). Allí, sobre la base del análisis formal de elementos, se define la alfarería Inca Cuzqueña, de origen netamente imperial; la alfarería Inca Provincial, que copia los cánones estilísticos del núcleo con una producción local; la alfarería Inca Mixta, la cual reúne tanto elementos cuzqueños como otros de filiación alterna (Diaguita-Inca p.e.); y la Alfarería Aconcagua de la Fase Inca, sin elementos foráneos (Tabla 5).

En el presente sitio no se registran piezas asignables a la alfarería Inca Cuzqueña e Inca Provincial. Sin embargo se registran cuatro vasijas para 
la tercera clase cerámica, las que evidencian ciertos elementos clásicos de la alfarería Incaica que se encuentran alterados en forma o decoración y/o se fusionan con elementos propios de las tradiciones alfareras locales, clase cerámica conocida también como Inca Local. Se trata, en parte, de los dos aríbalos registrados en la muestra (Vasija 1 Tumba 6, Vasija 3 Tumba 13).

\section{Tabla 5. Clases cerámicas del sitio Cementerio Estación Quinta Normal}

Table 5. Ceramic types from Quinta Normal Station Cemetery site

\begin{tabular}{|c|c|c|c|c|c|}
\hline 冚 & $\begin{array}{l}: \frac{\pi}{3} \\
\frac{\pi}{2} \\
>\end{array}$ & $\begin{array}{l}\text { Tipo de } \\
\text { Artef. }\end{array}$ & Clase Cerámica & Motivos Decoración & Observaciones \\
\hline 6 & 1 & Aríbalo & $\begin{array}{l}\text { Inca Mixta de Chile } \\
\text { Central }\end{array}$ & 1 & \\
\hline 6 & 2 & Jarro & Aconcagua de la Fase Inca & 1 & \\
\hline 6 & 3 & Puco & Aconcagua de la Fase Inca & Cruz diametral & $\begin{array}{l}\text { Estilo } \\
\text { Aconcagua }\end{array}$ \\
\hline 6 & 4 & Olla & Aconcagua de la Fase Inca & 1 & \\
\hline 7 & 1 & Plato & $\begin{array}{l}\text { Inca Mixta (Diaguita- } \\
\text { Inca) }\end{array}$ & $\begin{array}{l}\text { Triáng. escalerado y } \\
\text { pestañas c/ grecas al } \\
\text { interior }\end{array}$ & $\begin{array}{l}\text { Plato Plano } \\
\text { Forma A }\end{array}$ \\
\hline 7 & 2 & Cuenco & Aconcagua de la Fase Inca & 1 & \\
\hline 8 & 1 & Jarro & Aconcagua de la Fase Inca & 1 & \\
\hline 8 & 2 & Puco & Diaguita de la Fase Inca & $\begin{array}{l}\text { Banda de triángulos y } \\
\text { grecas escaleradas }\end{array}$ & Puco Forma A \\
\hline 8 & 3 & Cuenco & Aconcagua de la Fase Inca & 1 & \\
\hline 10 & 1 & Plato & Aconcagua de la Fase Inca & Cruz diametral & \begin{tabular}{|l|} 
Estilo \\
Aconcagua \\
\end{tabular} \\
\hline 11 & 1 & Cuenco & Aconcagua de la Fase Inca & 1 & \\
\hline 13 & 1 & Jarro & Aconcagua de la Fase Inca & 1 & $\begin{array}{l}\text { Agujero de } \\
\text { "matado" }\end{array}$ \\
\hline 13 & 2 & Olla & Aconcagua de la Fase Inca & 1 & $\begin{array}{l}\text { Fragmentada y } \\
\text { restaurada }\end{array}$ \\
\hline 13 & 3 & Aríbalo & $\begin{array}{l}\text { Inca Mixta de Chile } \\
\text { Central (Diaguita-Inca) }\end{array}$ & $\begin{array}{l}\text { Banda } 8 \text { rombos retic., } \\
\text { triángulos rellenos y } \\
\text { elem. antrop. }\end{array}$ & \\
\hline 13 & 4 & Botella & Aconcagua de la Fase Inca & 1 & $\begin{array}{l}\text { Fragmentada y } \\
\text { restaurada }\end{array}$ \\
\hline 13 & 5 & Plato & $\begin{array}{l}\text { Inca Mixta de Chile } \\
\text { Central (Diaguita-Inca) }\end{array}$ & $\begin{array}{l}\text { Banda anular de zig-zag } \\
\text { múltiple }\end{array}$ & \begin{tabular}{|l|l} 
Escudilla \\
Forma B \\
\end{tabular} \\
\hline
\end{tabular}

El primero exhibe una forma aribaloide poco acabada, evocando al tipo Cuzco rojo y blanco (Rowe 1944), sin embargo no detenta ningún otro ele- 
mento más de los descritos para contenedores incaicos como los protúberos y modelados (Sanhueza 2001). El otro aríbalo, exhibe una morfología más típica para las definidas en Chile central, siendo la disposición de la decoración adscribible al tipo decorativo $\mathrm{B}$, variante $\mathrm{A}$, donde la decoración se dispone en una banda horizontal a lo largo de todo el cuerpo superior de la pieza (Sanhueza 2001) (figura 6a y 6b). Esta variedad no sería propia de la alfarería nuclear, detentando a nuestro parecer elementos Diaguitas zooantropomorfos, que se reconfiguran en una expresión de carácter abstracto (figura $6 c$ y 6d).

Además se encuentra una escudilla (vasija 1 tumba 7) que evidencia características decorativas y morfológicas Inca mixtas. Por una parte la forma general de la vasija se asocia a una expresión incaica, mientras que la disposición de los motivos remite más bien a una manifestación Diaguita. Específicamente, se trata de dos triángulos escalerados, que exhiben una greca en su interior, y generan una reflexión en espejo en $90^{\circ}$; a su vez la presencia de otros cuatro triángulos forman una disposición hexagonal de los motivos (Figura 7).

La última de estas piezas (vasija 5, tumba 13) también se vincula a expresiones Diaguita-inca, pues se trata de un plato plano con dos pares de protúberos opuestos adheridos al labio y una banda anular interior de patrón zig-zag asociada a expresiones decorativas Diaguita (Figura 8).
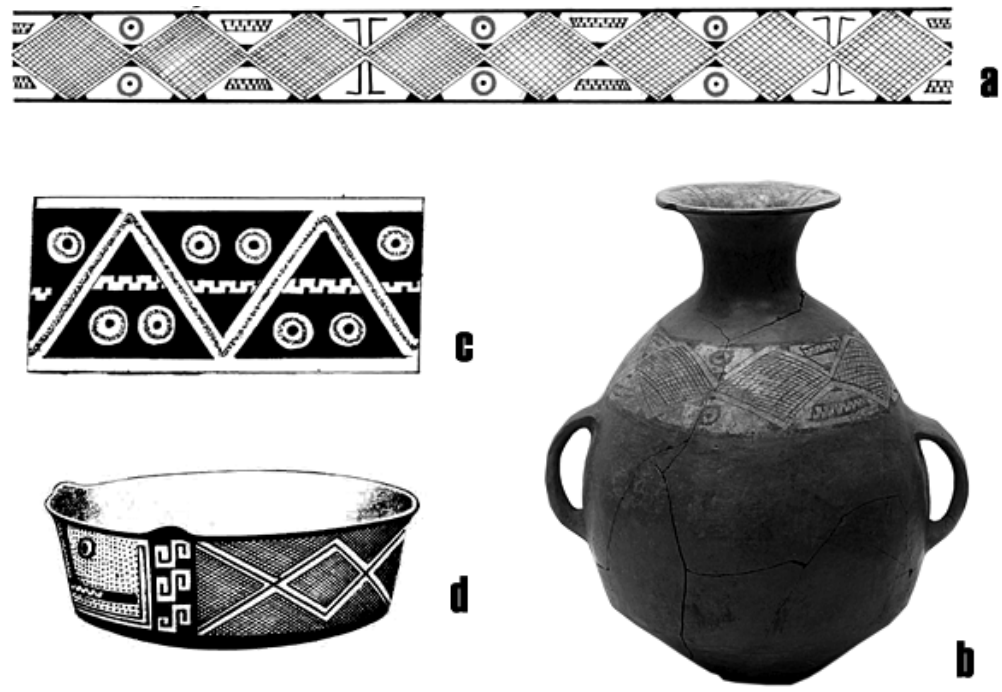

Figura 6: a) Visión extendida diseño banda aríbalo, b) vasija 3 tumba 13, c) Patrón Zig-Zag, procedente del rio Illapel (González 2004) d) Plato de Altovalsol, rio Elqui (Cornely 1962)

Figure 6: a) Extended view aribalo band design, b) vessel 3, tomb 13, c) Zig-Zag pattern from Illapel river (González 2004), d) Plate from Altovalsol, Elqui river (Cornely 1962). 

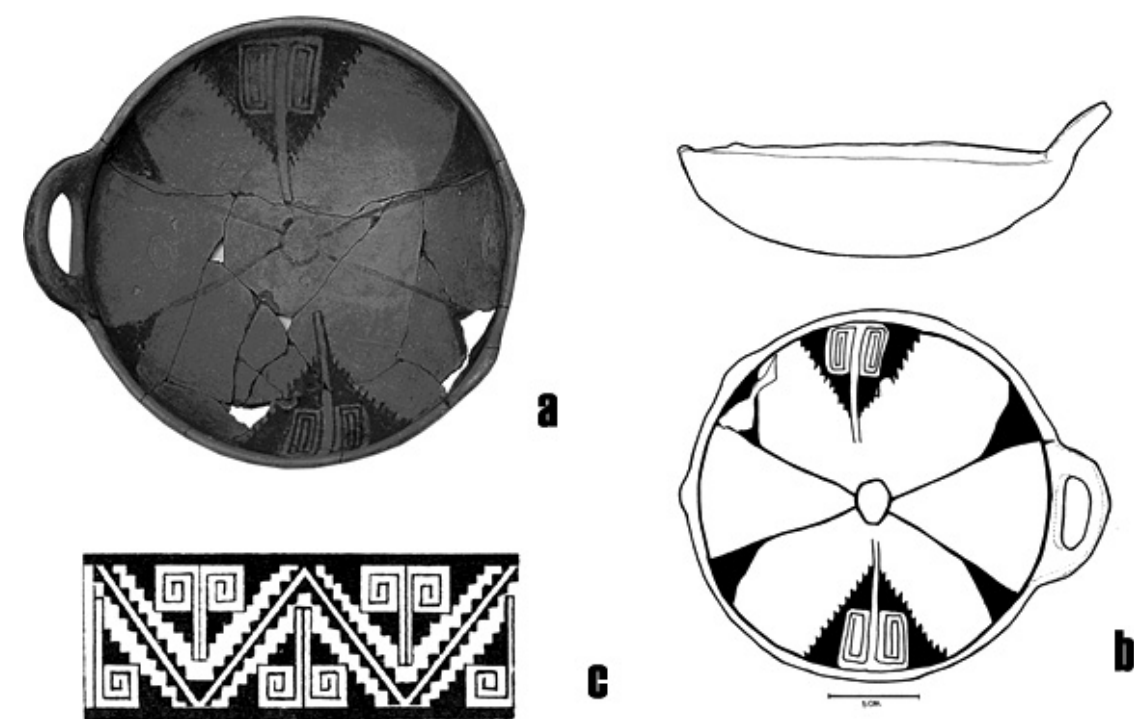

Figura 7: a y b) Vasija 1 de la tumba 7, c) Patrón zigzag J1, proveniente del valle de Elqui (Cornely 1962)

Figure 7: $a$ and b) Vessel 1 from tomb 7, c) Zig-Zag pattern J1 from Elqui valley (Cornely 1962)

En otros trabajos (Cantarutti 2002, Cantarutti y Mera 2004), se ha propuesto la existencia de una variedad cerámica Diaguita que muestra atributos de forma y/o decorativos de otras tradiciones. Lo anterior se ha entendido como híbridos que generan sincretismos con la población local. Anteriormente en este mismo cementerio se adscribió a esta categoría la vasija 1 de la tumba 5 que corresponde a un jarro pato, pieza característica de la fase Diaguita III, pero que difiere a escala estilística y morfológica de las piezas registradas en el Norte Chico (Cantarutti y Mera 2002).

En nuestro caso, la vasija 2 de la tumba ${ }^{\circ} 8$, presenta un motivo Diaguita patrón zigzag B (González 1995, 2004) (Figura 3 a y b) o patrón local (Cantarutti 2002 y 2004). La aparición de esta pieza en contextos funerarios de tiempos tardíos en Chile Central no nos otorga certeza respecto a la procedencia de su elaboración, por lo que cabe considerar esta vasija como una expresión Diaguita de momentos incaicos, sin una certeza respecto a su origen específico. 


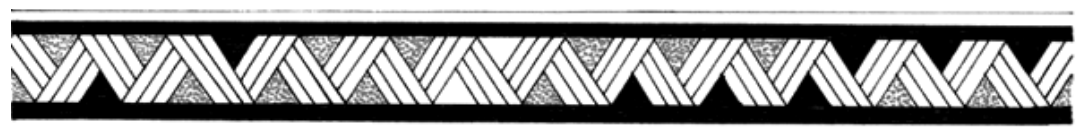

a
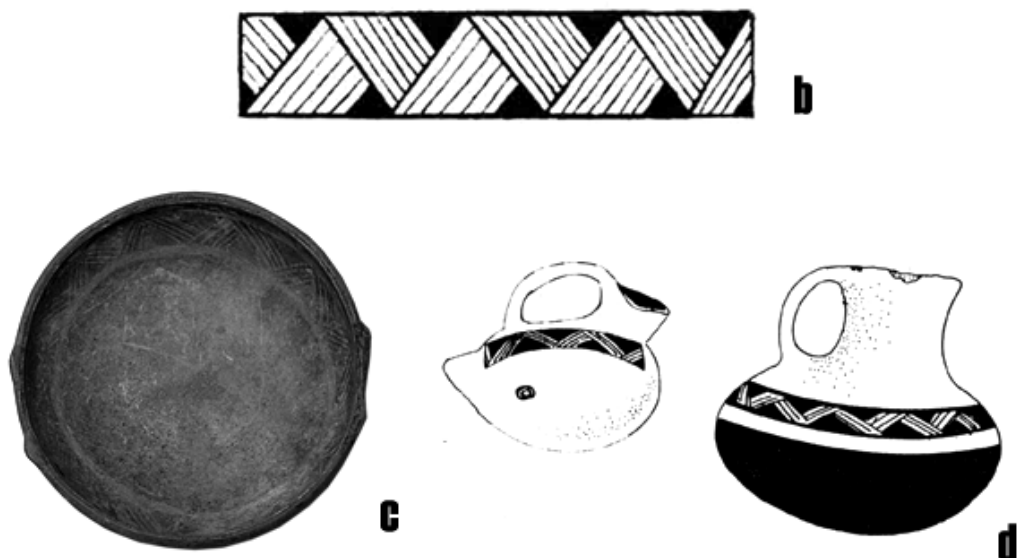

Figura 8: a) Visión extendida diseño escudilla b) Patrón zig-zag B, procedente del valle de Elqui (Cornely 1962) c) vasija 5 tumba 13, d) Patrón zig-zag B, procedente de vasijas del cementerio de Nos (Stehberg 1976)

Figure 8: a) Extended view escudilla design, b) Zig-Zag pattern B from Elqui valley (Cornely 1962), c) vessel 5, tomb 13, b) Zig-Zag pattern B from vessels of Nos cemetery (Stehberg 1976).

Finalmente, la variedad decorativa que presenta la vasija $n^{0} 5$ de la tumba 13, ha sido adscrita anteriormente como Aconcagua de la Fase Inca con Influencia Diaguita, a partir de la identificación con el patrón zig-zag Diaguita tipo B (Cantarutti y Mera 2002, González 2004). Sin embargo, este motivo también lo hemos podido identificar en otras tradiciones alfareras del período Intermedio Tardío como es la misma Aconcagua e incluso en la tradición bícroma rojo sobre blanco del complejo El Vergel (motivo zigzag múltiple Tipo 3) (Adán et al. 2005). De este modo, la evidencia abre la posibilidad a que estos motivos hayan sido compartidos a una mayor escala, siendo posiblemente originarios de la tradición Diaguita.

La mayoría de las vasijas de este estudio se enmarcan al interior de la clase cerámica definida como alfarería Aconcagua de la Fase Inca. Dentro de esta categoría se encuentran las vasijas pertenecientes a la tradición alfarera del complejo Aconcagua, que se manifiesta hacia tiempos tardíos durante la presencia del Inca en Chile Central, exhibiendo rasgos que las vinculan a los tipos cerámicos de este complejo cultural (Massone 1978) como las vasijas 3 y 4 de la tumba 6 , una de las cuales exhibe el clásico diseño de la cruz dia- 
metral (Figura 9), así como la pieza de la tumba 10, la vasija 2 del entierro 7 , la no3 de la tumba 8 , la única pieza ofrendada al individuo 11 , y la no 2 y 4 del entierro 13.

Con respecto a los tres jarros, sólo los rojos engobados, podrían acusar influencias Incaicas en el tratamiento de superficie, expresadas bajo una estética Aconcagua en la morfología. Por otra parte el último jarro monocromo (vasija no2, tumba 6 ) no posee rasgos diagnósticos que hicieran posible su asignación.
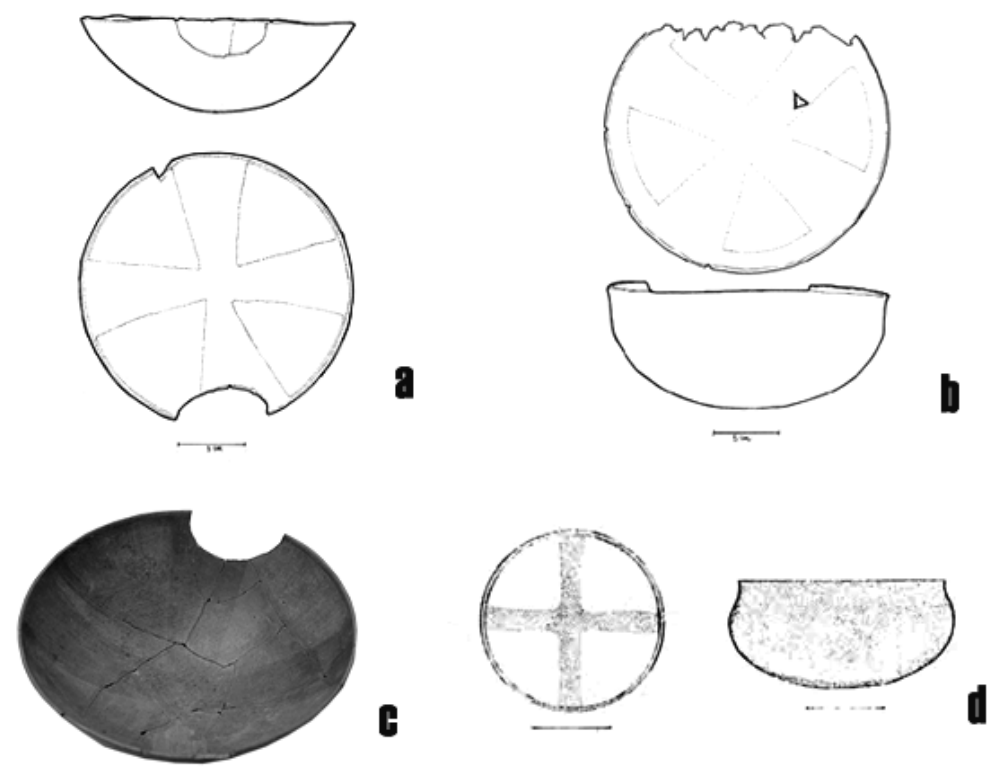

Figura 9: a y c) Vasija 1, Tumba 10, b) Vasija 3, Tumba 6, c) Escudilla con cruz diametral y cuenco Aconcagua de San Bernardo (Massone 1978)

Figure 9: a and c) Vessel 1, tomb 10, b) Vessel 3, tomb 6, c) Escudilla with diametrical cross and Aconcagua bowl from San Bernardo (Massone 1978)

\section{Discusión y CONCLUSIONES}

Entre las piezas cerámicas pertenecientes al ofertorio fúnebre del cementerio Estación Quinta Normal, no fueron registradas vasijas que pudieran ser asignadas como cuzqueñas, ni imitaciones fieles a dicha alfarería. Más bien se observa que la manifestación cerámica incaica se entrelaza con elementos de poblaciones Diaguitas en Chile Central, visualizado en cuatro piezas de carácter Inca Mixto. La presencia de estos ejemplares se conjuga con otras asignables a la tradición Aconcagua, entendidas como la manifestación cerámica de esta tradición para la fase inca, situación que también se 
observa en los enterratorios encontrados con anterioridad en este cementerio (Cantarutti y Mera 2002).

Desde el punto de vista del uso dado a las piezas descritas para el ofertorio cerámico de este cementerio, las huellas existentes se condicen con los datos referidos a los patrones de utilización detectados por Vásquez (1994) en piezas de contextos incaicos de Chile central (Marcoleta, Quilicura, La Reina, Nos, entre otros). En su investigación, el autor relaciona las funcionalidades descritas en los documentos etnohistóricos, donde se describe que los aríbalos (makas) y jarros, pertenecen al universo funcional, ligado a la contención y manipulación de líquidos; los platos (chuas) y pucos se asociarían al consumo cotidiano de alimentos y las ollas a la preparación de éstos (alta exposición al fuego). Así, las alteraciones de la superficie interna registradas en el aríbalo de la tumba 13, por ejemplo, podrían estar refiriéndose a lo señalado por este autor.

Por otra parte, se registra un notable tamaño y capacidad volumétrica de algunas piezas, tales como los dos aríbalos Inca mixtos o la gran botella de probable origen local. Con respecto a esto, algunos estudios que tratan sobre la producción y el uso de piezas incaicas en la zona, hablan de un aumento en el tamaño de los contenedores cerámicos, relacionado con unidades de consumo crecientes y vinculadas a una convocatoria mayor de personas, en función de una complejización de la estructura sociopolítica traída por el Inca (Vásquez 1994). En el caso del sitio analizado, algunos volúmenes alcanzan grandes dimensiones siendo equiparable a lo observado en otros sitios de la cuenca, como Las Tinajas de Quilicura y Nos (Cfr. Tabla 3).

Los grandes contenedores se verían relacionados con el almacenaje de alimentos para sostener actividades estatales, y por otro lado, la producción y ofrenda de chicha (como los aríbalos, y en nuestro caso la gran botella de la tumba 13) en contextos de festividad, ligados a la estructuración de alianzas y actividades de legitimación del poder (Vásquez 1994, Falabella et al. 2008).

Con relación a los contextos funerarios, contabilizando todas las tumbas descritas para esta área de enterratorios, se observa un alto número de individuos femeninos y una presencia generalizada de la ofrenda cerámica a la vez que se observa una variabilidad de formas y tipos decorativos presentes. Por otra parte, los trabajos de análisis contextual de la funebria Aconcagua (Durán 1979, Quevedo 1979, Sánchez 1995, González 2000) han señalado el carácter altamente selectivo de las ofrendas cerámicas, la cual se 
hace presente en pocos individuos, esencialmente masculinos, dando cuenta también de una sobreespecialización respecto a ciertas formas y diseños cerámicos. Hecho que denotaría otro orden, prácticas y patrones culturales hacia el Intermedio Tardío.

En tanto Bray (2003), a partir de una aproximación desde el género, señala la importancia de la mujer como partícipe en las relaciones de poder en la sociedad incaica. Éstas se involucrarían en la política de expansión del imperio, debido a su relación con el manejo de la vajilla como contenedor y elemento de materialización de las dádivas y festejos, realizados en el contexto de las reciprocidades y en el proceso de intercambio exogámico.

En estos contextos de carácter ritual, las relaciones de poder se hacen visibles a través de las dinámicas de eficacia simbólica materializadas por la alfarería. La vigencia de la tradición cultural Aconcagua ha sido vista por algunos como una ausencia de aculturación mayor de la población local por parte del Inca (Sánchez 2004). Por otro lado, esta interacción de expresiones cerámicas, que observamos en el cementerio estudiado y otros como los de Nos y Quilicura, puede hacernos pensar en la articulación de lo local con lo foráneo. Lo Aconcagua participa en conjunto tanto con lo Inca como con lo Diaguita, existiendo un reconocimiento de la identidad de cada uno, que se manifiesta en los contextos funerarios donde coexisten y a veces se fusionan las diversas expresiones cerámicas.

En Quinta Normal, la presencia netamente cuzqueña se encuentra ausente, estableciendo ésta una distancia con la tradición local, que se hace presente en otros espacios, como en el cementerio de La Reina y el santuario del cerro El Plomo. En nuestro caso, la presencia imperial se observa a través de una imposición, principalmente de las formas incaicas, como se puede observar en los platos y escudillas, junto a nuevas formas como el aríbalo. A su vez, la decoración evidencia modificaciones e híbridos que manifiestan elementos nortinos y locales, sin una clara presencia imperial, como se observa en otras áreas vinculadas al Tawantinsuyu, donde la producción alfarera se encontraría más relacionada con los cánones de producción nuclear del imperio (Bray 2004). La existencia de contenedores de filiación Diaguita, Diaguita-Inca y Aconcagua de la fase Inca grafican la articulación y fusión de múltiples identidades hacia momentos prehispánicos tardíos en Chile Central, hecho que reafirma la idea de un dominio diferencial sobre los distintos actores y ámbitos del quehacer social en esta región. Así, la cultura local Aconcagua y su relación con lo Inca se ve mediatizada por la cultura Diaguita, hecho observado en algunos ejemplares mixtos, mientras 
que en otros se expresa el claro sustrato local que se adapta al nuevo panorama cultural, donde la coexistencia de la producción alfarera implica el abandono de ciertas pautas y la adopción de nuevos rasgos.

Agradecimientos: Este trabajo se enmarca dentro la investigación generada en el contexto del proyecto "Estación de Intercambio Intermodal Quinta Normal" realizada durante el mes de julio del año 2006; dirigida por la investigadora Verónica Reyes, quien nos ha permitido analizar estos materiales. A su vez, merecen nuestra gratitud los evaluadores de este artículo por sus valiosos comentarios y observaciones. También se agradece a Claudio Rodríguez Aquea por sus acabadas ilustraciones.

\section{BiBLIOGRAFÍA}

Adán, L., R. Mera, M. Alvarado y M. Uribe. 2005. "La tradición cerámica bícroma rojo sobre blanco en la región sur de Chile: los estilos decorativos Valdivia y Vergel”. Actas del XVI Congreso Nacional de Arqueología Chilena, pp. 399-410, Concepción.

Bauer, B. 1996. El desarrollo del estado Inca. Centro de Estudios Regionales Andinos Bartolomé de Las Casas. Cuzco.

Bray, T. 2003. "Inca pottery as culinary equipment: food, feasting, and gender in imperial state design". Latin American Antiquity 14 (1): 3-28.

Bray, T. 2004. "La alfarería imperial Inca: una comparación entre la cerámica estatal del área de Cuzco y la cerámica de las provincias”. Chungara 36(2): 365-374.

Baudet, D. 2002. Análisis cerámico sitio Las Tinajas. Manuscrito en posesión de los autores.

Calderari, M. y V. Williams. 1991. "Re-evaluación de los estilos cerámicos Incaicos en el noroeste argentino". Comechingonia 9: 73-95.

Cantarutti, G. 2002. Estadio Fiscal de Ovalle: redescubrimiento de un sitio Diaguita - Inca en el valle de Limarí, IV Región de Coquimbo. Memoria para optar al título de Arqueólogo. Universidad de Chile, Santiago.

Cantarutti, G. y R. Mera. 2002. "Alfarería del cementerio estación Matucana: ensayo de clasificación y relaciones con la cerámica del período Inca de Chile central y áreas vecinas". Revista Werkén 3: 147-170.

Cantarutti, G. y R. Mera. 2004. "Estadio Fiscal de Ovalle: Redescubrimiento de un sitio Diaguita-Inca en el valle de Limari”. Chungará 36: 833-845. 
Referencias Bibliográficas: Las referencias en el texto deben ajustarse al formato (autor, año) en caso de no ser citas textuales y (autor, año: página) en caso de ser citas textuales. Al final del escrito, tras sección agradecimientos se deben incluir las referencias de todos los textos citados, en orden alfabético y ajustándose a la siguiente normativa.

Artículos en Revistas:

Munizaga, C. 1984. Ciudad y vecinos: cuatro ideas para la enseñanza de la vida urbana. Revista Chilena de Antropología 4: 11-30.

Falabella, F.; M.T. Planella, E. Aspillaga, L. Sanhueza y R. Tykot. 2007. Dieta en sociedades alfareras de Chile central: Aporte de análisis de isótopos estables. Chungará 39 (1): 5-27.

\section{Libros:}

Salinas, F. 2007. Pensar, Sentir, Actuar. Método en Antropología Social. Editorial Universidad Bolivariana, Santiago.

\section{Capitulo de Libro:}

Escobar, A. 2000. El lugar de la naturaleza y la naturaleza del lugar: ¿Globalización o Postdesarrollo? En La colonialidad del saber: eurocentrismo y ciencias sociales, perspectivas latinoamericanas, editado por E. Lander, pp: 113-143. FLACSO, Buenos Aires.

\section{Artículo en Actas de Congreso, Simposio o Seminario:}

Niemeyer, H. 1977. Variación de los estilos de arte rupestre en Chile. Actas del VII Congreso de Arqueología de Chile, tomo II, pp: 649-660. Altos de Vilches, Chile.

Memorias y Tesis

Castro, V.1997. Huacca Muchay. Evangelización y Religión Andina en Charcas, Atacama La Baja. Tesis para optar al grado de Magíster en Historia, Mención Etnohistoria, Departamento de Ciencias Históricas, Universidad de Chile, Santiago.

Notas: corresponden a notas al final del artículo y tras la sección Referencias Bibliográficas. Se deben usar sólo excepcionalmente y deben ir numeradas secuencialmente en el texto. Deben utilizar letra Times New Roman, punto 10 y números arábicos.

Tablas: Deben ser incluidas en hoja aparte, tras sección notas. Todas las tablas deben ser antecedidas por una numeración correlativa en sistema arábico y un título que indique su contenido. Su título debe estar en español e inglés.

Figuras: Deben listarse posterior a las notas, en hoja aparte, incluyendo la leyenda de cada una en español e inglés. Las imágenes no se deben incluir en el texto y deben ser enviadas en formato digital, formato TIFF, EPS o Photoshop. Se priorizarán imágenes en blanco y negro. En caso de que las imágenes excedan la posibilidad de 
Cornejo, L. 2001. "Alfarería y Política". En: Tras la Huella del Inca en Chile, pp:114-119, Museo Chileno de Arte Precolombino, Santiago.

Cornely, F. 1962. El arte decorativo pre-Incaico de los indios de Atacama y Coquimbo (Diaguitas Chilenos). Ilustre Municipalidad de La Serena, La Serena.

D’Altroy, T. 1992. Provincial Power in the Inka Empire. Smithsonian Institution Press. Washington y Londres.

D'Altroy, T. 2003. The Incas. Blackwell Publishing, Oxford.

Dillehay T. y A. Gordon. 1988. "La actividad prehispánica de los Incas y su influencia en la Araucanía”. En La frontera del estado Inca, T. Dillehay y P. Netherly (eds), pp: 215-234. BAR, Oxford.

Durán, E. 1979. "El yacimiento de María Pinto, sus correlaciones y ubicación temporal". Actas del VII Congreso Nacional de Arqueología Chilena, tomo I: 261-275. Altos de Vilches.

Falabella, F.; M. Planella, y R. Tykot. 2008. "El maíz (Zea mays) en el mundo prehispánico de Chile Central”. Latin American Antiquity 19(1):25-46.

González, C. 2000. "Comentarios arqueológicos sobre la problemática Inca en Chile central (primera parte)". Boletín de la Sociedad Chilena de Arqueología 29: 39-50.

González, P. 1995. Diseños cerámicos de la Fase Diaguita-Inca: Estructura, simbolismo, color y relaciones culturales. Memoria para optar al título de Arqueólogo. Universidad de Chile, Santiago.

González, P. 2000. “Diseños cerámicos diaguita y diseños cerámicos Aconcagua: Diferenciación e interrelaciones desde una perspectiva estructural". Actas del XIV Congreso Nacional de Arqueología Chilena tomo I: 337-368, Copiapó.

González, P. 2004. "Arte visual, espacio y poder: manejo Incaico de la iconografía cerámica en distintos asentamientos de la fase Diaguita-Inca en el valle de Illapel”. Chungara Volumen Especial, Tomo II: 375-392.

Leiva, D. 2006. Informe de excavación cementerio Inca - Quinta Normal. Manuscrito en posesión de los autores.

Massone, M. 1978. Los tipos cerámicos del complejo cultural Aconcagua. Tesis de Licenciatura en Arqueología y Prehistoria. Universidad de Chile, Santiago.

Mostny, G. 1947. "Un cementerio incásico en Chile central”. Boletín del Museo Nacional de Historia Natural XXIII: 17-41. 
Mostny, G. 1957. "La momia del cerro El Plomo". Boletin del Museo Nacional de Historia Natural 27 (1):109-112.

Murra, J. 1975 (1972). "El control vertical de un máximo de pisos ecológicos en la economía de las sociedades andinas”. En: Visita a la Provincia de León de Huanuco en 1562, J. Murra (ed), pp. 429-476. Huanuco.

Planella, M.T. y R. Stehberg. 1997. "Intervención Inka en un territorio de la cultura local Aconcagua de la zona centro-sur de Chile". Tawantinsuyu 3: 58-78.

Quevedo, S. 1979. "Estudio de los restos óseos de una población agroalfarera prehistórica: María Pinto”. Actas del VII Congreso Nacional de Arqueología Chilena, tomo I: 277-289. Altos de Vilches.

Raffino, R. 1981. Los inkas del Kollasuyu. Ramos Americana, Buenos Aires.

Raffino, R. 1993. Inka. Arqueología, Historia y Urbanismo del Altiplano Andino. Ediciones Corregidor, Buenos Aires.

Raffino, R. y R. Stehberg. 1997. "El Tawantinsuyu y sus fronteras". Actas y trabajos cientificos XI Congreso Peruano del Hombre y la Cultura Andina "Augusto Cardich”. Tomo I: 338-361.

Reyes, V.; M. Henríquez y J. Sanhueza. 2005. "Cementerio Incaico Estación Quinta Normal, Línea 5 del Metro de Santiago”. Actas del XVI Congreso Nacional de Arqueología Chilena, pp: 655-664. Concepción.

Rostworowski, M. 1988. Historia del Tawantinsuyu. Instituto de Estudios Peruanos, Lima.

Rowe, J. 1944. "An introduction to the archaeology of Cuzco". Papers of the Peabody Museum of American Archaeology and Ethnology Vol. XXVII (2).

Rowe, J. 1945. "Absolute Chronology in the Andean Area". American Antiquity $10,265-284$.

Sánchez, R. 1995. Complejo cultural Aconcagua: hacia una definición de los principios que organizan su estructura interna. Informe Proyecto Fondecyt $\mathrm{N}^{\circ} 1940463$. Conicyt, Santiago.

Sánchez, R. 2003. El Tawantinsuyu en el curso superior del río Aconcagua. Una interpretación de su presencia. Tesis presentada para obtener el grado de Magíster en Arqueología. Universidad de Chile, Santiago.

Sánchez, R. 2004. "El Tawantinsuyu en Aconcagua (Chile central)". Chungara 36 (2): 325-336. 
Sanhueza, L. 2001. "El aríbalo Inca en Chile central". Werkén 2: 47-69.

Sanhueza, L. y E. Latorre. 2006. Informe cerámica sitio Intermodal Quinta Normal, etapa evaluación y compensación recursos arqueológicos. Manuscrito en posesión de los autores.

Stehberg, R. 1976. "La fortaleza de Chena y su relación con la ocupación Incaica de Chile central". Publicación Ocasional 23: 3-37.

Stehberg, R. 1995. Instalaciones incaicas en el norte y centro semiárido de Chile. Dirección de Bibliotecas Archivos y Museos, Santiago.

Troncoso, A. 2005. "El plato zoomorfo/antropomorfo Diaguita: una hipótesis interpretativa". Werkén 6: 113-124.

Uribe, M. 1999-2000. "La arqueología del Inca en Chile". Revista Chilena de Antropología 15: 63-97.

Vásquez, M. 1994. "Contextos cerámicos Incaicos en Chile central". Actas del $2^{\circ}$ Taller de Arqueologia de Chile Central, disponible en http://www.arqueología.cl.

Wachtel, N. 1973. Sociedad e ideología, ensayos de historia y antropología andina. Instituto de estudios peruanos, Lima.

Williams, V. y T. D'Altroy. 1998. “El sur del Tawantinsuyu: Un dominio selectivamente intensivo". Tawantinsuyu 5: 170-178.

Williams, V. 2004. "Poder estatal y cultura material en el Qollasuyu". Boletin de arqueología PUCP 8: 209-245.

Zuidema, T. 1964. The Ceque System of Cuzco: The Social Organization of the Capital of the Inka. Internacional Archives of Ethnography. Suplement to vol. 50. E.J. Brill, Leiden. 
露 